\title{
Parkinson disease and Ayurveda
}

\begin{abstract}
Parkinson's disease, a degenerative brain disease of dopamine secreting brain cells Substantia nigra is increasing progressively and presents therapeutics -levodopa, carbidopa, MAOB inhibitor, COMT inhibitors, surgery and deep brain stimulations, though improve presenting feature but not quality of life. Present study using herbal composite containing Mucuna pruriens, Herpestis monnieri,Acors calamus, Nardostachys jatamansi and Withania somnifera taken in equal partshows better quality of life in all most all with marked improvement in movemement disorder in $92 \%$ cases as compared to $39 \%$ cases on conventional therapy. In addition Herbal composite also improve the haematological, hepatic and Renal function by bioregulating body biomechanics and neural cell function, revitalizing neural cell damage in substantia nigra check distruction of dopamine and facilitate optimal level of Dopamine for normal brain function.
\end{abstract}

Keywords: parkinson disease, substantia nigra, dopamine, livodopa, carbidopa, MAOB inhibitor, COMT inhibitor, deep brain stimulation
Volume 9 Issue 5 - 2019

\author{
Avinash Shankar, 'Amresh Shankar, ${ }^{2}$ Anuradha \\ Shankar ${ }^{3}$ \\ 'Postgraduate in Endocrinology \& Metabolism, National Institute of \\ Health \& Research, India \\ ${ }^{2}$ Hon Director, Aarogyam Punarjeevan, India \\ ${ }^{3}$ Senior Research Fellow cum Medical Officer, Regional Institute of \\ Ayurveda Research, India
}

Correspondence: Avinash Shankar, Postgraduate in

Endocrinology \& Metabolism (AlIMS-Delhi), National Institute of

Health \& Research, Warisaliganj, Bihar, 805।30, India,

Email dravinashshankar@gmail.com

Received: July II, 2019 | Published: September 03, 2019

\section{Introduction}

Parkinson disease is a chronic progressive and degenerative disease of Central Nervous System and presents with movement disorders which prompt handicap in long time. ${ }^{1-3}$ This is considered as a combination of genetic susceptibility, exposure to one or more disease triggering environmental factor. ${ }^{4,5}$ Clinical manifestations are solely due to degenerative change in substantia nigra, a seat of an important neuro transmitter synthesis i.e.- Dopamine and $60-80 \%$ loss of dopamine secreting cells presents with dreaded presentation of movement disorder i.e.- tremor, rigidity, bradykinesia, postural instability. In addition changing dietary habits and lifestyle causes free radical accumulation also triggers the clinical presentation. ${ }^{6-14}$

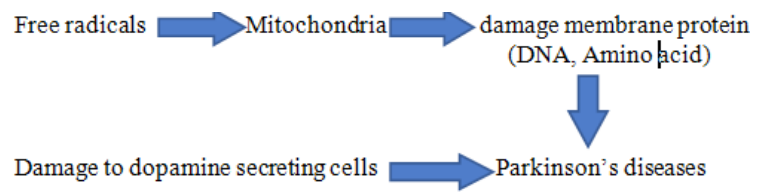

The commonest diagnostic tool remain the clinical acumen but MRI is considered commonly prescribed investigation as CSF examination remain non conclusive. ${ }^{15}$ Commonly prescribed therapeutics are levodopa, carbidopa, MAO B inhibitor and COMT inhibitor, Presently surgery and deep brain stimulation are also quite in vogue. ${ }^{16,17}$

Long term Levodopa use is frequently associated with serious impact on patents quality of life, inhibition of peripheral amino acids decarboxylase is administered to achieve proper dopamine concentration in Central Nervous System.

Inspite of all the available therapeutic modalities incidence of Parkinson's disease increasing and affects $1 \%$ of the people above the age of 65 years and presently it is 247 per lakh. There is no homogenous and large epidemiological data on PD from India. Razdan et al. reported a crude prevalence rate of 14.1 per 100,000 amongst a population of 63,645 from rural Kashmir in the northern part of India. The prevalence rate over the age of 60 years was $247 / 100,000$. Thus today's need is safe affordable and curative therapeutics.

\section{Objective of the study}

Evaluate the comparative therapeutic efficacy of herbal composit in management of parkinsons disease.

a. Design of the study: Comparative.

b. Interest of conflicts: None.

c. Ethical committee: Ethical committee approves the evaluation of status of safe herbal composit in management of Parkinson disease.

\section{Material and methods}

\section{Material}

Patients attending neuro clinic of RA Hospital \& Research Centre Warisaliganj (Nawada) and Aarogyam Punrjeevan, Patna 14 having complaints of movement disorders were considered for the proposed study. Patients with severe debility, bed ridden and associated other disease like diabetes mellitus and hypertension were excluded from the study.

\section{Methods}

Selected patients and their attendants were thoroughly interrogated for their presenting features, their duration, age of onset, disease progression, treatment taken, their effects and adversity. Patients were clinically examined and investigated for their basic bio-parameters to adjudge the effect of drug or drug related adversity.

Selected patients were graded as per clinical presentation (as per Hochu and Yahr sstaging ) 


\section{Stages Characteristics}

I Symptoms of one side of the body

II Symptoms on both side of the body, no balance impairment

III Balance impaired, physically independent

IV Severe debility and still able to walk or stand

$\mathrm{V}$ Wheel chair or bed ridden

Selected patients were classified in two groups having equal number of patients with similar status and each group were advised.

Group A: conventional treatment with Levodopa/carvidopa.

Group B: Herbal composite.

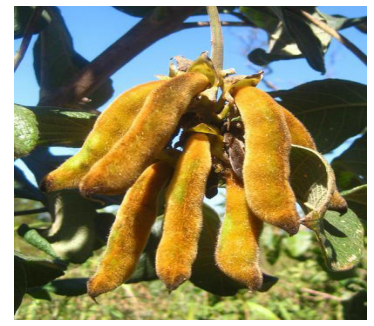

Mucuna Pruriens Seed

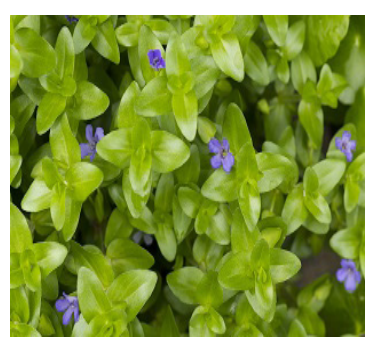

Herpestis Monnieri

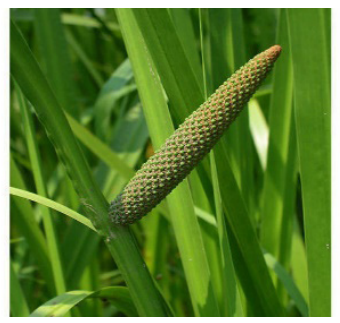

Acorus Calamus Acorus

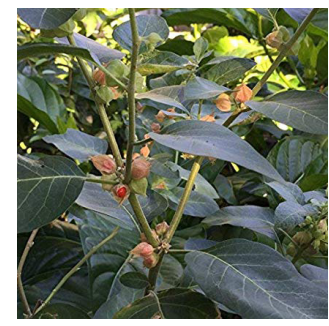

Withania Somnifera

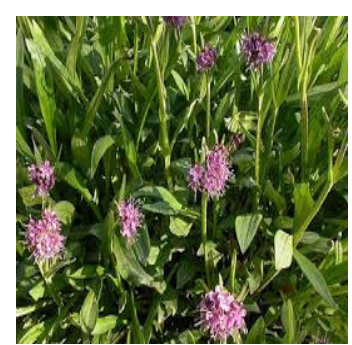

Nardostachys Jartamansi

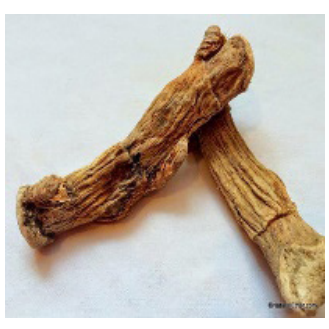

Calamus Rhizome

\section{Each Capsules of 500mg constitutes equal part of}

Mucuna Pruriens Seed 100mg

Withania Somnifera Root 100mg

Herpestis Monnieri Leaf 100mg

Nardostachys Jatamanshi 100mg

Acorus Calamus Rhizome 100mg
Dose schedule: 1 caps every 8hours. Each patient were given a follow up card to enter the changes in movement, stability and handwriting with an instruction to attend the centre on every alternate Friday for first 6 months and every 3 months afterward. Patients were followed by the Medical social worker of the organization to ascertain the changes in clinical presentation. To adjudge the improvement in CNS function handwriting was analysed digitally on tab. Clinical response was adjudged as

\section{Clinical grade \\ Excellent Complete absence of movement abnormality without any adjuvant, drug adversity and withdrawal or relapse. \\ Good Marked improvement in clinical presentation with occasional dystonia. \\ Poor No drug adversity, Only transient relief with frequent recurrence and adversity.}

\section{Observation}

Selected patients were of age group 40->60years with male predominance over the female and majority patients were of age $>60$ years, $73.7 \%$ male and $26.3 \%$ female were of age group $55-60$ years, $6.6 \%$ of $40-45$ years, $26.3 \%$ were of $>60$ years (Figures $1 \&$ 2). Out of all $12.5 \%$ were taking treatment since last $1-2$ years, $27 \%$ sine $4-5$ years while $24.3 \%$ since $>5$ years (Figure 3 ). $22.4 \%$ were presenting with movement disorder, $45.4 \%$ with movement disorders on both side and $29 \%$ with balance disorder (Table 1). As per clinical severity $22.4 \%, 45.4 \%, 29 \%$ and $3.2 \%$ are of stage I, II, III and IV respectively (Figure 4). Out of all basic bio parameters of the selected

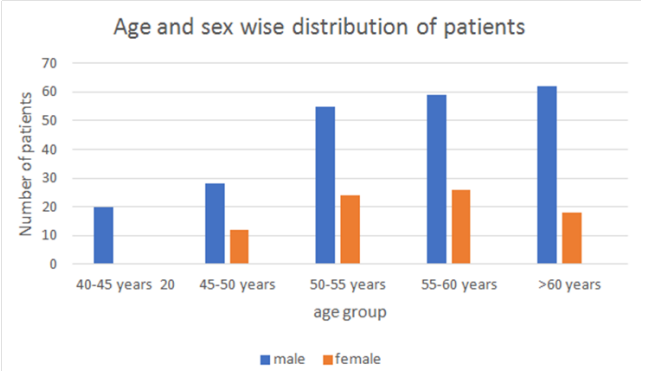

patients $77.6 \%$ patients had haemoglobin $<10$ gram $\%$, Serum bilirubin $>1 \mathrm{mg} \%$,SGOT and SGPT $>30$ IU, Alkaline phosphatase 130 in $5.3 \%$, blood sugar (Fasting) $>100 \mathrm{mg} \%$ in $3.3 \%$ cases (Table 2 ).

Figure I Bar diagram showing age and sex wise distribution of patients.

Table I Showing distribution of patients as per their presentation

\begin{tabular}{ll}
\hline Clinical presentation & $\begin{array}{l}\text { Number of } \\
\text { patients }\end{array}$ \\
\hline $\begin{array}{l}\text { Movement disorder on one side of } \\
\text { the body }\end{array}$ & 68 \\
$\begin{array}{l}\text { Movement disorder on both side of } \\
\text { the body }\end{array}$ & 138 \\
$\begin{array}{l}\text { Balance impairment } \\
\text { Severe debility }\end{array}$ & 88 \\
Wheel chair or bed ridden & 10 \\
\hline
\end{tabular}


Table 2 Showing basic bio -parameters

\begin{tabular}{|c|c|}
\hline Basic bio parameters & Number of patients \\
\hline \multicolumn{2}{|l|}{$\begin{array}{l}\text { Haematological } \\
\text { Haemoglobin }\end{array}$} \\
\hline$<\operatorname{logm}$ & 236 \\
\hline$>10 \mathrm{gm} \%$ & 68 \\
\hline \multicolumn{2}{|l|}{ Hepatic profile } \\
\hline \multicolumn{2}{|l|}{ Serum bilirubin } \\
\hline$<\operatorname{lmg} \%$ & 236 \\
\hline$>$ Img\% & 68 \\
\hline \multicolumn{2}{|l|}{ SGOT } \\
\hline$<30 I U / L$ & 236 \\
\hline$>30 I U / L$ & 68 \\
\hline \multicolumn{2}{|l|}{ SGPT } \\
\hline$<30 \mid U / L$ & 236 \\
\hline$>30 I U / L$ & 68 \\
\hline \multicolumn{2}{|l|}{ Alkaline phosphatise } \\
\hline$<100$ & 288 \\
\hline$>100$ & 16 \\
\hline \multicolumn{2}{|l|}{ Diabetic profile } \\
\hline \multicolumn{2}{|l|}{ Blood sugar } \\
\hline \multicolumn{2}{|l|}{ Fasting } \\
\hline$<100 \mathrm{mg} \%$ & 294 \\
\hline$>100 \mathrm{mg} \%$ & 10 \\
\hline \multicolumn{2}{|l|}{ Renal profile } \\
\hline \multicolumn{2}{|l|}{ Blood urea } \\
\hline$<30 \mathrm{mg} \%$ & 304 \\
\hline$>30 \mathrm{mg} \%$ & - \\
\hline \multicolumn{2}{|l|}{ Serum Creatinine } \\
\hline$<1.5 \mathrm{mg} \%$ & 304 \\
\hline$>1.5 \mathrm{mg} \%$ & - \\
\hline
\end{tabular}

Male Female Composition

Figure 2 Pie diagram showing male: female composition.

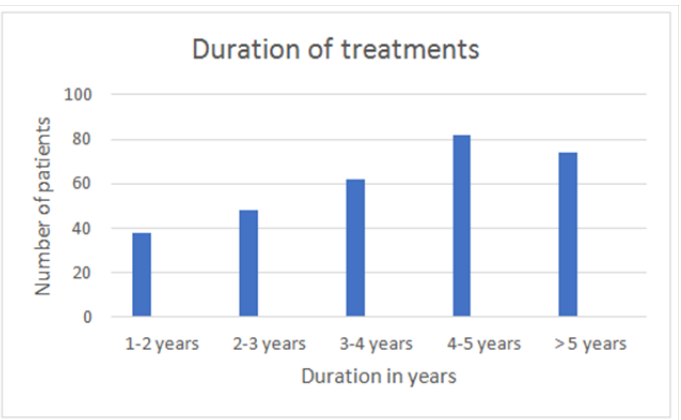

Figure 3 Bar diagram shows duration of past treatment.

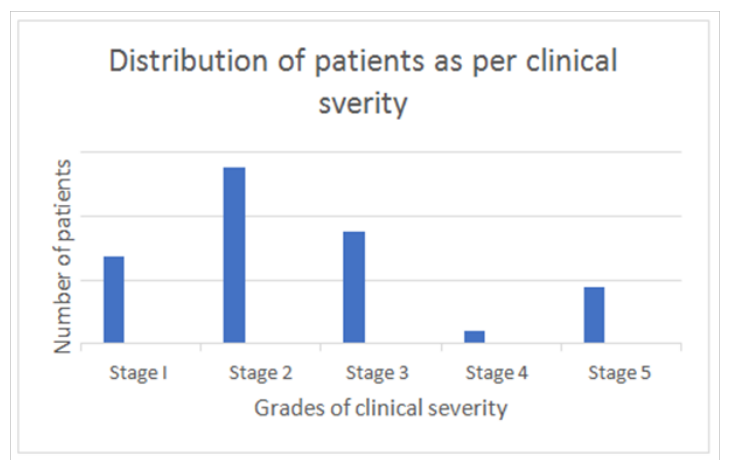

Figure 4 Bar diagram showing Distribution of patients as per clinical severity

\section{Result}

Patients on herbal composite shows early and better movement improvement as adjudged by handwriting or hand movement (ascertained digitally)than other group i.e.- 92\% patients on herbal composite had normal hand writing while on conventional therapy only $39 \%$ cases (Figure 5). Therapeutic outcome is better in both cases i.e. herbal composite alone or herbal composite with conventional drug than mere conventional therapy, almost $100 \%$ than $22.4 \%$ on conventional therapy. Post therapy bioparameters get improved in all the cases on Herbal composite than 02 patients on conventional therapy had worsening of parameters.

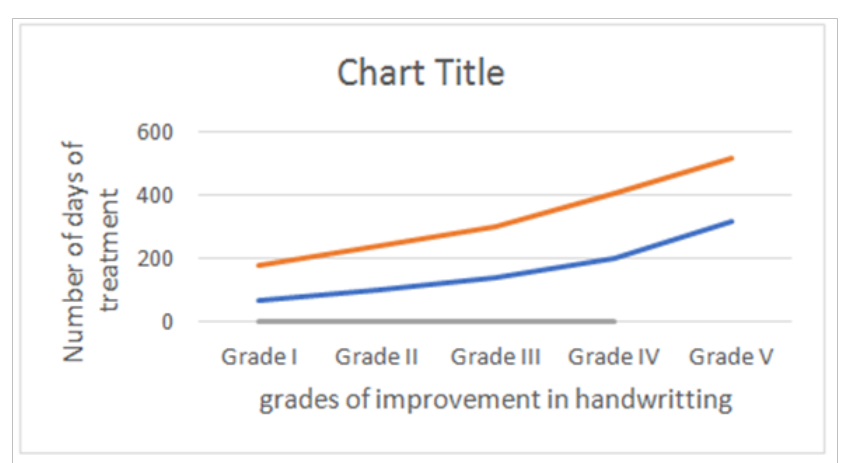

Figure 5 Graph showing improvement in handwriting in mean duration of treatment.

\section{Discussions}

Parkinson disease affecting elderly and more male than female result in handicap and bed ridden in spite of advanced therapeutics like surgery and deep brain stimulation, current therapeutics though control movement disorder but fails to improve quality of life. Present study of comparative evaluation of herbal composite versus conventional therapeutics shows superiority of herbal composite than conventional i.e.- $92 \%$ patients on Herbal composite had grade I clinical recovery and better quality of life without any adversity or disease related sequel or required any adjuvant as compared to $39 \%$ on conventional therapeutics and is attributed to -

Mucuna pruriens: Provides Natural Levodopa to suppliment Dopamine.

Herpestis monnieri: Revitalize damaged neyral cells in substantia nigra.

Nardostachys jatamansi: Check degeneration of neural cells in substantia nigra.

Acorus calamus: Check metabolism of existing Dopamine. 
Withania simnifera: Bioregulate body biokinetics -improve quality of life.

Hence combinely produce sustained improvement and bioregulate movement synegy, check degeneration of neural cells in substantia nigra, trevitalize damaged cell with provision of natural Levodopa (Figure 7). ${ }^{18-33}$

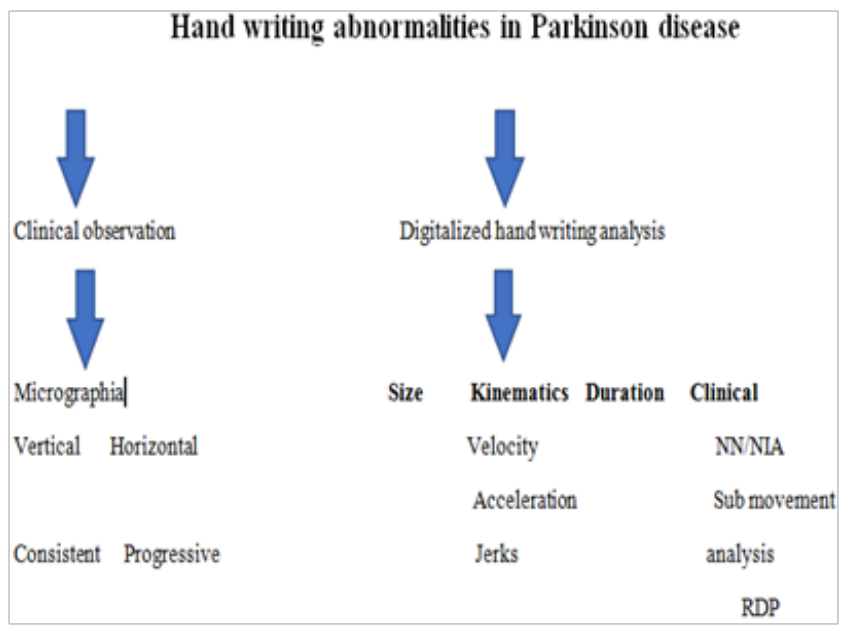

Figure 6 Showing hand writing changes.

\begin{tabular}{|c|c|c|c|c|c|}
\hline \multicolumn{6}{|c|}{ Parkinson disease } \\
\hline & Stage I & Stage II & Stage III & Stage IV Stage V & \\
\hline & 68 & 138 & 88 & 44 & \\
\hline \multicolumn{6}{|c|}{ Selected patient } \\
\hline \multicolumn{6}{|c|}{304} \\
\hline & Group A & & & & Group B \\
\hline & (152) & & & & (152) \\
\hline & Tìal drug & & & & Conventional therapy \\
\hline \multicolumn{6}{|c|}{$A^{2}$} \\
\hline & Only trial drug & \multicolumn{3}{|c|}{ Tinal drug phus continuing duug } & \\
\hline Outcome: & $A 1$ & $A^{2}$ & & B & \\
\hline Grade I & 75 & 76 & & 34 & \\
\hline Grade II & 01 & $\cdot$ & & 110 & \\
\hline Grade III & . & $\cdot$ & & 08 & \\
\hline \multicolumn{6}{|c|}{ Post therapy bio parameter: } \\
\hline Unchanged & & 76 & & 150 & \\
\hline Changed & & - & & 02 & \\
\hline Unine album & & & & 01 & \\
\hline $\begin{array}{l}\text { Raised SGOT } \\
\& S G P T\end{array}$ & T. & - & & 02 & \\
\hline $\begin{array}{l}\text { \&SGPT } \\
\text { Decteased H }\end{array}$ & & . & & 02 & \\
\hline
\end{tabular}

Figure 7 Outcome of the study.

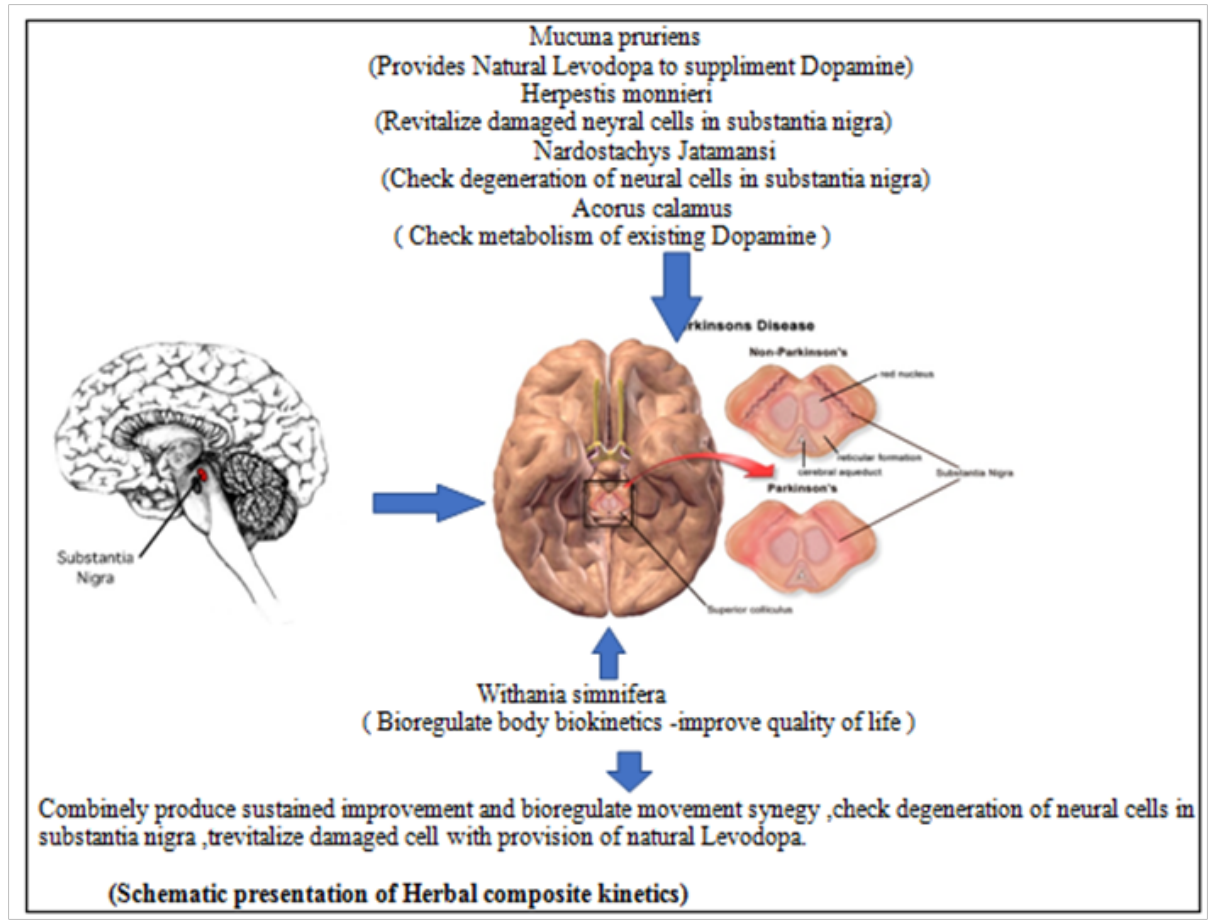

Figure 8 Shows Herbal composite bio-kinetics.

\section{Conclusion}

Herbal composite constituting equal parts of Mucuna pruriens, Herpestis monnieri, Acorus calamus, Nardostachys jatamansi and Withanis somnifera. Proves worth in patients of Parkinson's disease in alleviating clinical presentation and improving quality of life without any untoward effects or withdrawal manifestation.

\section{Acknowledgments}

None.

\section{Conflict of interest}

The authors declare that there is no conflict of interest. 


\section{Funding}

None.

\section{References}

1. Pearce JM. Aspects of the history of Parkinson's disease. J Neurol Neurosurg. 1989;Suppl:6-10.

2. Singhal B, Lalkaka J, Sankhla C. Epidemiology and treatment of Parkinson's disease in India. Parkinsonism Relat Disord. 2003;9(Suppl 2):S105-109.

3. de Lau LM, Breteler MM. Epidemiology of Parkinson's disease. Lancet Neurol. 2006;5(6):525-235.

4. Das SK, Biswas A, Roy T, et al. A random sample survey for prevalence of major neurological disorders in Kolkata. Indian $J$ Med Res. 2006;124(2):163-172.

5. Ragothaman M, Murgod UA, Gururaj G, et al. High occurrence and low recognition of Parkinsonism (and possible PD) in old age homes in Bangalore, South India. J Assoc Physicians India. 2008;56:233-236.

6. CM T, DW G, CG G. A brief screening questionnaire for parkinsonism. Ann Neurol. 1990:267-288.

7. Behari M, Srivastava AK, Das RR, et al. Risk factors of Parkinson's disease in Indian patients. J Neurol Sci. 2001;190(1-2):49-55.

8. Streifler M, Hofman S. Disorders of verbal expression in parkinsonism. Adv Neurol. 1984;40:385-393.

9. Singh S, Behari M. Verbal and visual memory in patients with early Parkinson's disease: Effect of levodopa. Neurol India. 2006;54(1):33-37.

10. Arun MP, Bharath S, Pal PK, Singh G. Relationship of depression, disability, and quality of life in Parkinson's disease: A hospital-based case-control study. Neurol India. 2011;59(2):185-189.

11. Kumar S, Bhatia M, Behari M. Sleep disorders in Parkinson's disease. Mov Disord. 2002;17(4):775-781.

12. Giovannoni G, van Schalkwyk J, Fritz VU, et al. Bradykinesia akinesia inco-ordination test (BRAIN TEST): an objective computerised assessment of upper limb motor function. J Neurol Neurosurg Psychiatry. 1999;67(5):624-629.

13. Durif F, Vidailhet M, Debilly B, et al. Worsening of levodopa-induced dyskinesias by motor and mental tasks. Mov Disord. 1999;14:242-245.

14. Markham CH, Diamond SG. Evidence to support early levodopa therapy in Parkinson disease. Neurology. 1981;31(2):125-131.

15. Gupta D, Saini J, Kesavadas C, et al. Utility of susceptibility-weighted MRI in differentiating Parkinson's disease and atypical parkinsonism. Neuroradiology. 2010;52(12):1087-1094.

16. Yadav R, Shukla G, Goyal V, et al. Knowledge of Parkinson's disease among patients and caregivers attending movement disorder clinic at a tertiary care centre in north India. Ann Indian Acad Neurol. 2012;15(4):294-296.
17. Katzenschalger R, Evans A, Manson A, et al. Mucuna Pruriens in Parkinson 's disease: a Double-blind Clinical and Pharmacological Study. J Neurol Neurosurg Psychiatry. 2004;75(12):1672-1677.

18. Manyam B. Paralysis agitans and levodopa in "Ayurveda": ancient Indian medical treatise. Mov Disord. 1990;5(1):47-48.

19. Manyam B, Sanchez-Ramos JR. Traditional and complementary therapies in Parkinsońs disease. Adv Neurol. 1999;80:565-574.

20. Damodaran M, Ramaswamy R. Isolation of L-dopa from the seeds of Mucuna pruriens. Biochem J. 1937;31(12):2149-2451.

21. HP-200 in Parkinson's Disease Study Group. An alternative medicine treatment for Parkinson's disease: results of a multicenter clinical trial. $J$ Altern Complement Med. 1995;1(3):249-255.

22. Vayda AB, Rajgopalan TS, Mankodi NA, et al. Treatment of Parkinsońs disease with the cowhage plant - Mucuna pruriens (Bak). Neurol India. 1978;26(4):171-176.

23. Nagashayana N, Sankarankutty P, Nampoothirir MR, et al. Association of L-dopa with recovery following ayurveda medication in Parkinson's disease. J Neurol Sci. 2000;176(2):124-127.

24. Rinne UK, Sonninen V, Sirtola T. Plasma concentration of levodopa in patients with Parkinson's disease. Eur Neurol. 1973;10(5):301-310.

25. Jaffe M. Clinical studies of carbidopa and L-dopa in the treatment of Parkinson's disease. Adv Neurol. 1973;2:161-72.

26. Reid JL, Calne DB, Vakil SD, et al. Plasma concentration of levodopa in parkinsonism before and after inhibition of peripheral decarboxylase. $J$ Neurol Sci. 1972;17(1):45-51.

27. Pinder RM, Brogden RN, Sawyer PR, et al. Levodopa and decarboxylase inhibitors: a review of their clinical pharmacology and use in the treatment of Parkinsonism. Drugs. 1976;11(5):329-377.

28. Kurth MC, Tetrud JW, Irwin I, et al. Oral levodopa/carbidopa solution versus tablets in Parkinson's patients with severe fluctuations: a pilot study. Neurology. 1993;43:1036-1039.

29. Tripathi YB, Upadhyay AK. Effect of the alcohol extract of the seeds of Mucuna pruriens on free radicals and oxidative stress in albino rats. Phytother Res. 2002;16(6):534-538.

30. Kuopio AM, Marttila RJ, Helenius H, et al. The quality of life in Parkinson's disease. Mov Disord. 2000;15(2):216-223.

31. Ray J, Das SK, Gangopadhya PK, Roy T. Quality of life in Parkinson's disease - Indian scenario. J Assoc Physicians India. 2006;54:17-21.

32. Shankar A. Pharmacokinetics of constituent herbs, Pharmacological basis of indigenous therapeutics. $1^{\text {st }}$ edn. India: Bhalani Publishing House; 2009. 